Original Article

\title{
Unfolding Various Concepts of Junctional Epithelium
}

\author{
Bhavana Puvvalla ${ }^{1}$, Suchetha A. ${ }^{2}$, Darshan B. M undinamanae ${ }^{3}$, Apoorva S.M. . ${ }^{4}$, Divya Bhat ${ }^{5}$ \\ ${ }^{1}$ Post graduate student, ${ }^{2}$ Professor and Head of the department, ${ }^{3,4}$ Reader, ${ }^{5}$ Senior lecturer, Department of Periodontology, \\ D.A.P.M .R.V. Dental college, Bangalore
}

Corresponding author: Bhavana Puvvalla, Post graduate student, Department of Periodontics, D.A.P.M .R.V. Dental college, Bangalore, Mobile : +919342414744E-mail : bannuu03@gmail.com

Received

: 05.12.2017

Review Completed : 08.01.2018

Accepted

$\cdot 10.02 .2018$

Keywords: Junctional epithelium, Barrier, Periodontal disease, implant surface, oral microflora.

\begin{tabular}{|c|}
\hline Access this article online \\
\hline Quick Response Code \\
\hline
\end{tabular}

\begin{abstract}
The Gingival epithelium comprises of three different areas based on their anatomical and functional points of view 1) the oral or outer epithelium (OGE), 2) Sulcular epithelium (SE) and 3) Junctional epithelium (JE). The junctional epithelium may be regarded as the most interesting structure of the gingiva. . The formation of junctional epithelium in the implant/ mucosal interface can be considered as the first barrier of defense against oral micro flora. Any kind of disruption of this barrier will lead to initiation and progression of progression of periodontal disease. Hence, in this review we made an attempt to wrap various concepts of junctional epithelium formation, its role in disease progression and its relation to the implant surface.
\end{abstract}

\section{Introduction}

Junctional epithelium (J.E) rather than simply providing an attachment to the tooth surface it actively participates in host defense mechanisms. Hence it is regarded as the most interesting structure of gingiva. ${ }^{[1]}$ The key function of J.E is to clear and thwart the continuous bacterial challenge by allowing the cells and substances to emigrate from the sulcus into the gingival connective tissue considering it as an 'open system'. ${ }^{[2]}$ Amongst the gingival epithelium a spot light on J.E is important because of its location anatomically and as because it is the site of host-bacterial interaction in the initiation of periodontal disease.

\section{Definitions}

"A unique squamous non-keratinized epithelium that forms the base of the gingival sulcus and adheres to both tooth and the underlying lamina propria at the base of the gingival crevice formerly called as epithelial attachment" AAP. $^{[3]}$

"The Junctional epithelium is the epithelial component of the dento-gingival unit that is in contact with the tooth surface" - Bosshardt and Lang. ${ }^{[2]}$

\section{Terminologies}

Epithelial attachment - Gottelieb 1921

Epithelial cuff - Waerhaug 1952

Attached epithelial cuff - Orban 1956

Junctional epithelium - Stern 1967

\section{Concepts of Junctional Epithelium}

The history of the development, structure and dynamics of the epithelial attachment, has been reviewed and retold since many years.

G.V. Black (1915) suggested that as the tooth erupts into the oral cavity, the oral and odontogenic epithelium fuse to form a continuous lining. According to Black, at the CEJ the apical end of the sulcular epithelium was only attached. ${ }^{[4]}$

M icroscopically the presence of a firm attachment around the tooth was first demonstrated by Gottelieb (1921) which he termed as "epithelial attachment". ${ }^{[5]}$ 
Holton (1937) concluded that there was no real connection found to exist between enamel and epithelium with the introduction of dyes into the attachment.

Waerhaug (1952) observed that the epithelial cells attached to the surface of artificial crowns which were in contact with the pocket epithelium was due to adhesion and described this junction as the EPITHELIALCUFF. ${ }^{[6]}$

Orban (1960) demonstrated a firm attachment of epithelial cells to the teeth in his experimental study where he inserted steel blades into the sulci of dogs and monkeys. This experiment was in agreement with the Gottelieb's concept of firm attachment. ${ }^{[7]}$

Listgarten (1966) felt that epithelial cells attach to the tooth by means of hemidesmosomes and a basement membrane (basal lamina) despite their origin, whether derived from reduced ameloblasts or oral epithelium.
Since cells move along the tooth surface from the apical portion of the epithelial attachment to the base of the sulcus this attachment is not considered static. ${ }^{[5]}$

Stern (1981) reported a width of lamina lucida is $400 \mathrm{~A}^{0}{ }^{[6]}$

Sabag et al (1981) described that 4 to 8 hemidesmosomes at the coronal zone and 2 hemidesmosomes in the apical zone mediate the epithelial attachment to the cementum root surface concluding that more adhesion is exhibited by the coronal zone of cemental surface when compared to apical zone. ${ }^{[6]}$

The opinion that attachment to the tooth surface may occur even without the cuticle being present and the cuticle only represents an accumulation of material from metabolites of plaque, which was suggested by Friedman in 1993. ${ }^{[7]}$

\section{Development of the Junctional Epithelium:}

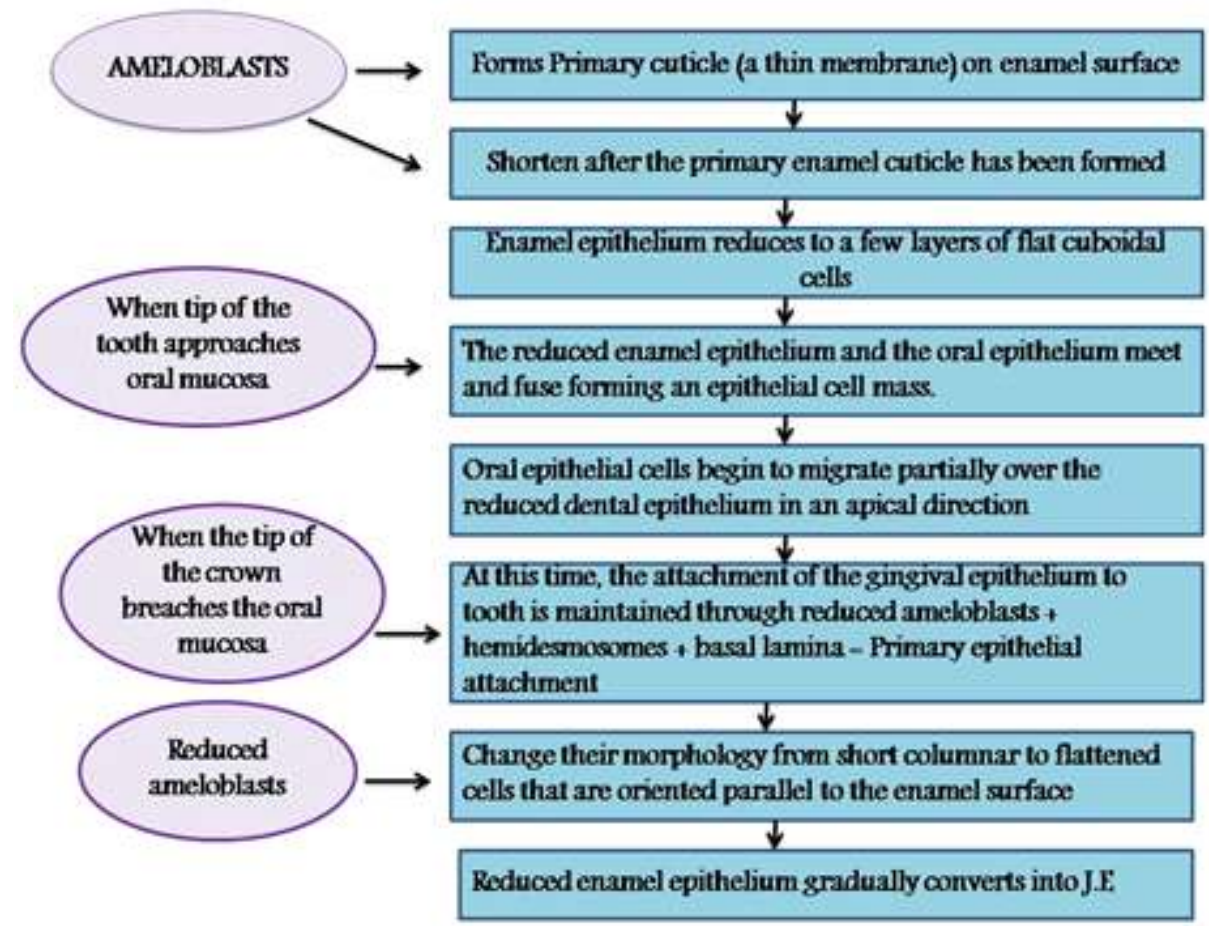

The final conversion of reduced enamel epithelium to a stratified squamous epithelium may not occur until 34years after the tooth has erupted. ${ }^{[8]}$

The development of the dento-gingival junction may be regarded as complete, immediately after all the reduced enamel epithelium has been transformed into the squamous epithelium.

At this time, it extends to the cemento-enamel junction and its epithelial component consists of junctional epithelium, formed largely by transformation of reduced 
enamel epithelium. Interface between J.E and the tooth surface forms? secondary epithelial attachment. ${ }^{[9]}$

\section{Anatomy of the Junctional Epithelium:}

Junctional epithelium is stratified squamous non keratinizing epithelium which forms a collar like band peripheral to the cervical region of tooth. JE coronally terminates as a free surface which is located at the base of sulcus. Length of JE is 0.25 to 1.35 according to Carranza; and according to Gargiulo is $0.71 \mathrm{~mm}-1.35 \mathrm{~mm}$. ${ }^{[10]}$ The epithelial seal extends from CEJ to marginal gingiva under pristine conditions which is $2 \mathrm{~mm}$ in height and is attached to the tooth surface (epithelial attachment) by the internal basal lamina and to the gingival connective tissue (basal layer) by an external basal lamina. ${ }^{[11]}$ (Figure 1)



FIGURE 1,

Histological diagram showing the number of junctional epithelial cells 1 to 3 cells at the apical zone where as $15-30$ cells at the coronal zone

\section{Cellular inclusions of Junctional Epithelium:}

The basal cell layer and the adjacent 1 to 2 suprabasal cell layers are cuboidal to slightly spindle shaped and the remaining layers of suprabasal cell layers are flat, oriented parallel to the tooth surface, and closely resemble each other. (Figure 2)

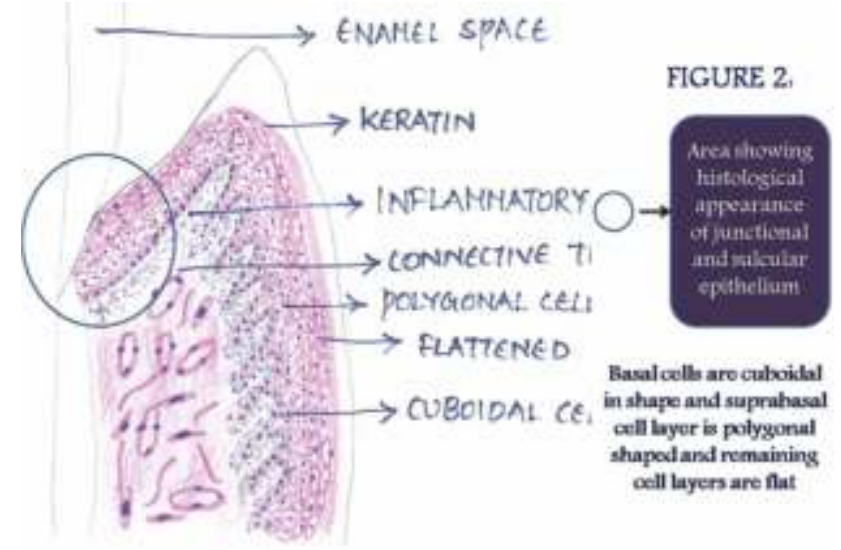

The inner most suprabasal cells facing the tooth surface are also called as DAT cells (Directly Attached to Tooth) (Salonen et al., 1989). ${ }^{[12]}$

In general, the transformation of gingival sulcus to periodontal pocket is the result of disturbances or imbalance between microbial attack and host defence mechanisms. Locally, this process includes the degeneration and detachment of coronal DAT cells from the tooth surface. DAT cells forms and maintains the 'internal basal lamina' that faces the tooth surface and these cells may also share some additional characteristics with the basal cells since they have the ability to form an attachment. ${ }^{[13]}$ M orphologically, DAT cells vary from low cuboidal to flatten cells. This variation in cell morphology did not correlate with the cells potential to synthesize DNA instead the prerequisite for DNA synthesis is the capability of attachment of individual suprabasal cells to the tooth surface. $^{[14]}$

Along with the DAT Cells, lysosomal bodies, cytokeratins, polymorph nuclear lymphocytes are found in J.Ecells.

Lysosomal bodies are found in more numbers in J.E cells. Enzymes contained within these lysosomes share a role in the eradication of bacteria. ${ }^{[15]}$

Cytokeratins belong to intermediate filament (IF) protein family that provides mechanical support and fulfil a variety of functions in epithelial cells. ${ }^{[16]}$ Cytokeratin distribution varies in different epithelia; its distribution in oral epithelium is different from junctional epithelial complex which is adjacent to the tooth surface.

Various cytokeratins detected immune histochemically in J.E are CK 19, CK 16, CK 14, CK 13, CK 6, CK 5, and CK 4. According to the findings of Juhl et al CK13 is more frequently found in the coronal part of JE and is considered to be a differentiation marker for non-

keratinized squamous epithelia. ${ }^{[17]} \mathrm{A}$ study was done by Feghali-Assaly et al to identify the above mentioned cytokeratins in partially erupted human dentition and concluded that the following cytokeratins are seen in PJE (Primary junctional epithelium) $^{[18]}$ 
PJE In Basal layers - CK 19, 16, 13 and 4 mRNAs were abundant

In Supra basal layers - CK 19 less concentrated but CK 13 and 4 is abundant

Neutrophilic granulocytes are the immune defense cells of the J.E, also called as polymorphonuclear leukocytes, neutrophils and PM Ns. They are abundantly found in the central region of the J.E (Schroeder and Listgarten 1997). ${ }^{[19]}$ $>50 \%$ of the leukocytes infiltrating the J.E and $90 \%$ of the leukocytes isolated from the crevicular fluid are neutrophils. The periodontal tissues neutrophilic concentration exceeds the blood neutrophil concentration. ${ }^{[20]}$ (Table 1)

Table 1

\begin{tabular}{|l|l|}
\hline TISSUE & COUNT OF NEUTROPHILS \\
\hline $\begin{array}{l}\text { Connective tissue of minimally } \\
\text { infiltrated gingiva }\end{array}$ & $2.5 \times 10^{7} \mathrm{PM} \mathrm{N} / \mathrm{cm}^{3}$ \\
\hline $\begin{array}{l}\text { Junctional epithelium of minimally } \\
\text { inflamed gingiva }\end{array}$ & $1.7 \times 10^{8} \mathrm{PM} \mathrm{N} / \mathrm{cm}^{3}$ \\
\hline Blood levels of neutrophils range & $1 \times 10^{6}$ to $4 \times 10^{6} \mathrm{PM} \mathrm{N} / \mathrm{cm3}$ \\
\hline
\end{tabular}

The epithelial attachment: The basement membrane is made up of external and internal basal lamina. The external basal lamina lies between internal basal lamina and basal cells of J.E. The internal basal lamina is found to be continuous with the external basal lamina at the apical end of junctional epithelium. ${ }^{[21]}$ By means of internal basal lamina together with the hemidesmosomes the junctional epithelium is attached to the tooth surface. This is called epithelial attachment (Figure 3 and 4).

\section{FIGURE 3}

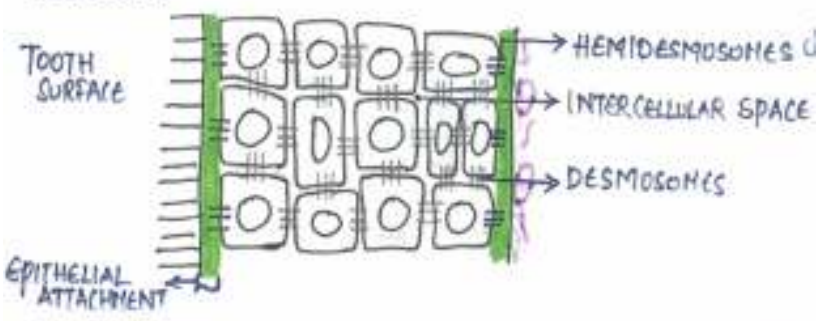

Diagrammatic representation of various intercellular junctions (hemidesmosomes and desmosomes)

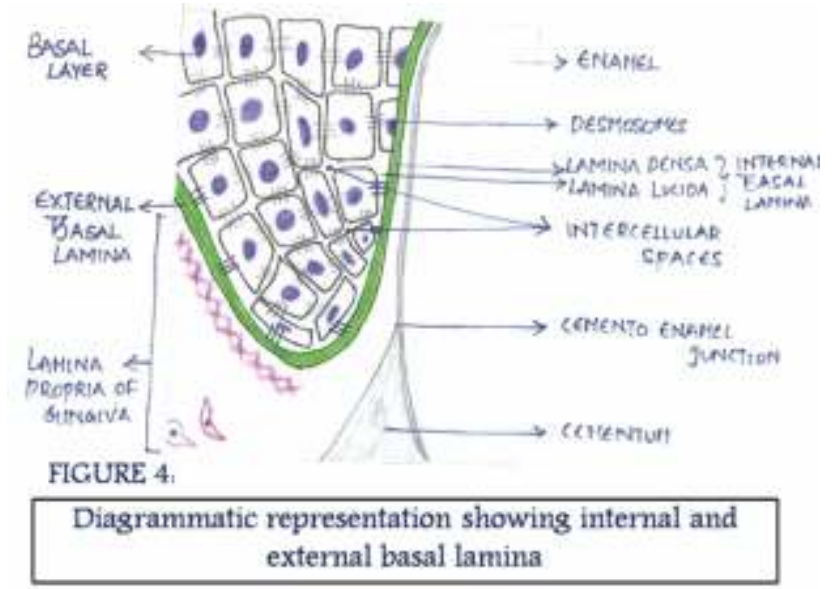

Basement membrane operate special functions like

1. Compartmentalization (physical barrierfunction),

2. Filtration (selective permeability barrier function),

3. Cell polarization,

4. Migration,

5. Adhesion, and

6. Differentiation ${ }^{[22]}$

Internal basal lamina consists of;

a) Lamina lucida also called as Lamina rara

b) Lamina densa

c) Lamina Fibroreticularis also called as Sub-basal lamina.

Sub basal lamina faces the connective tissue and forms a layer of reticular and anchoring fibrils. Generally, basement membrane matrix typically constitutes type IV and type VII collagen, laminin, heparan sulfate, proteoglycan, fibronectin, nidogen (entactin), and the proteoglycan perlecan, while the basement membrane of J.E lacks most of these constituents like as collagen types IV and VII, most laminin isoforms, perlecan. ${ }^{[23]}$ Thus, the internal basal lamina of J.E cannot be regarded as basement membrane as it hasits own characteristics.

\section{IntercellularJunctions}

There are various cell junctions in epithelial tissues and play a key role in enabling communication between neighbouring cells via specialized proteins called communicatingjunctions.

Generally, there are three major types of cell junctions:

a) Anchoring junctions 
b) Gapjunctions (communicating junction)

c) Tightjunctions (occluding junctions) ${ }^{[24]}$

Three types of anchoring junctions are noticed; they are desomosomal junctions, hemidesmosomal junctions and adherens junctions and they differ from one another in their cytoskeleton anchor and the Trans membrane linker. ${ }^{[25]}$ (Table 2)

Table 2

\begin{tabular}{|l|l|l|l|}
\hline Junction & Desmosomes & $\begin{array}{l}\text { Hemides- } \\
\text { mosomes }\end{array}$ & $\begin{array}{l}\text { Adherens } \\
\text { junctions }\end{array}$ \\
\hline $\begin{array}{l}\text { Cytoskeleton } \\
\text { anchor }\end{array}$ & $\begin{array}{l}\text { Intermediate } \\
\text { filaments }\end{array}$ & $\begin{array}{l}\text { Intermediate } \\
\text { filaments }\end{array}$ & $\begin{array}{l}\text { Actin } \\
\text { filaments }\end{array}$ \\
\hline $\begin{array}{l}\text { Transmembrane } \\
\text { linker }\end{array}$ & Cadherin & Integrins & $\begin{array}{l}\text { Cadherin/ } \\
\text { Integrins }\end{array}$ \\
\hline Ties cell to & Other cells & EC matrix & $\begin{array}{l}\text { Other cells/ } \\
\text { ECmatrix }\end{array}$ \\
\hline
\end{tabular}

Gap junctions are also called as nexus or macula communicans and are specialized intercellular connections which directly connect the cytoplasm of two cells. These gap junctions allow various molecules, ions and electrical impulses to directly pass through a regulated gate between the cells. ${ }^{[26]}$

Tight junctions also known as occluding junctions or zonulae occludentes (Singular, Zona occludens) are composed of a branching network of sealing strands. Therefore, the efficiency of the junction in preventing ion passage increases exponentially with the number of strands. ${ }^{[27]}$

J.E cells are interconnected by few desmosomes and occasional gap junctions contrary to stratified squamous gingival epithelium whose cells are connected by all the three types of junctions.

\section{Innervations}

The junctional epithelium is well innervated by sensory nerve fibers especially the basal cell layers, which have been subsequently been confirmed by immunocytochemical studies. ${ }^{[2,29]}$ These studies observed that several dense nerve plexus are distributed and detected in the apical two-thirds of the epithelium, near the gingival sulcus and the enamel surface. Tanaka and co- workers they employed substance $P$, calcitonin generelated peptide (CGRP) and neurokinin-1 receptor and demonstrated the existence of nerve terminals. In the intercellular spaces between basal cells of junctional epithelium substance P- axon profiles were detected immune histochemically. ${ }^{[30]}$

\section{Dynamics of the Junctional Epithelium}

Knowledge about progressive alteration of cellular and extracellular aspects of J.E is important as these dynamics are crucial in maintaining its protective and regenerative functions.$^{[31]}$ The characteristic feature of J.E in primates is its high cellular turn over which

is about 1 week to 10 days. ${ }^{[32]}$ Turn over happens by mitotic cell division which is seen at the basal cell layers and DAT cells and the subsequent migration of cells towards the coronal direction resulting in gradual exfoliation of daughter cells from the free surface of J.E. Also, Since the DAT cells are connected to the basal lamina the DAT cells are said to migrate towards the bottom of the sulcus. Thus, the epithelial attachment is dynamic not static. ${ }^{[33]}$

\section{Role of JE in Antimicrobial Defence}

A variety of molecules are transported by the tissue fluid to the bottom of gingival sulcus through the J.E. These molecules along with PMNs they represent host immune defense mechanism against the bacterial insults. Approximately 30,000 PM Ns per minute migrate into the oral cavity through the J.E in the absence of clinical signs of inflammation. Thus, gingival fluid is considered as an exudate and its flow rate is directly proportional to the degree of inflammation.

Various mechanisms involved in antimicrobial defense:

1. High turnover rate of J.E is crucial in antimicrobial defense

2. The surface area of J.E is 50 times larger and hence allows for effective flow of epithelial cells and impedes bacterial colonization and thus acts as an effective barrier. This is called as Funnelling effect.

3. Defensins and lysosomal enzymes produced by the cells of J.E which functions as antimicrobial defense 
4. Chemokines which are secreted by activated epithelial cells attracts various cells like defensins and lymphocytes which activate further inflammatory process. $^{[2]}$

\section{Role of the Junctional Epithelium in the initiation of Pocket Formation}

Pocket formation initiates by detachment of DAT cells from tooth surface. A biologically relevant and clinically important question raised by Schroeder (1996) is: 'what happens to the junctional epithelium under conditions of sub-gingival microbial attack, i.e., in context with pocket formation and deepening?' This question still awaits resolution but meanwhile several researchers have attributed the formation of pocket to a loss of cellular continuity in the coronal-most portion of the $] . E .^{[34]}$

Clinically, factors of both microbial and host origin alter the $\mathrm{JE}$ in several ways like the attachment apparatus between the JE and the teeth can be broken down (or) the biosynthetic function of the DAT cells can be altered (or) cell lysis can be induced (or) renewal of the DAT cells can be inhibited. ${ }^{[35]}$

Takata and Donath (1988) ${ }^{[36]}$ studying pocket formation in humans, observed degenerative changes in the second or third cell layer of the DAT cells in the coronal-most portion of the junctional epithelium facing the bacterial biofilm. Similar observations were made in a dog model. ${ }^{[37]}$ Several attempts to explain the reason for the cleavage within the junctional epithelium have been made. With increasing degrees of gingival inflammation, both the emigration of PMNs and the rate of gingival crevicular fluid passing through the intercellular spaces of the junctional epithelium increase. ${ }^{[38]}$ Moderately distended intercellular spaces are not considered to interfere with the structural and functional integrity of the junctional epithelium. However, an increased number of mononuclear leukocytes, i.e., T- and B-lymphocytes and monocytes/ macrophages, together with PMNs, are considered as factors that contribute to the focal disintegration of the junctional epithelium. ${ }^{[39]}$ Apart from the view that the host itself is the major source of factors contributing to the disintegration of the junctional epithelium, other possibilities have to be considered as well.

Various factors of both microbial and host origin which can clinically alter J.E, they are:

1. The attachment apparatus between the JE and the teeth can be broken down

2. DAT cells biosynthetic function can be altered

3. Stimulation of DAT cell lysis

4. DAT cell lysis renewal inhibited

All these mechanisms ultimately lead to degenerative changes in JE which further promote detachment of epithelium from the root surface and subsequently lead to periodontal pocket formation. But, this is not thoroughly being studied and the development of optimal model systems is still in progress. Thus, the development of pocket is attributed to detachment of the DAT cells or to the development of an intra-epithelial split.

\section{Junctional Epithelium and Microbiota}

The Junctional epithelium allows various cells and molecules to migrate into the sulcus from gingival connective tissue which helps in fighting against continuous bacterial invasion, and

in contrast bacterial cells are also permeable to enter into J.E hence it is considered as "Open system". It has already been studied that the pocket formation results due to subgingival spread of microbiota under impaired defense conditions ${ }^{[40]}$ So, various authors have further extended their studies ${ }^{[14,42,43]}$ to know about various mechanisms exercised by microbiota in the destruction of J.E. However, amongst all microbiota, a keen interest is paid to know the mechanisms played by Actinobacillus actinomycetemcomitans (A.A comitans) and Porphyromonas gingivalis (P. gingivalis) to adhere, replicate and invade epithelial cells.

Cysteine proteinases produced by P.gingivalis commonly regarded as Gingipains ${ }^{[44]}$, specially degrade cell-cell epithelial junctional complexes leading to proteolysis of focal contact components, adhesion signaling molecules, adherens junction proteins, reduced adhesion to 
extracellular matrices, changes in morphology, impaired motility, and apoptosis.

Various studies have also reported that Gingipains disrupts the ICAM -1-dependent adhesion of PM Ns to oral epithelial cells allowing P.gingivalis to enter J.E leading to proteolytic disruption of the epithelial integrity, a significant factor in pocket formation initiation.

\section{Junctional Epithelium adjacent to Oral Implants}

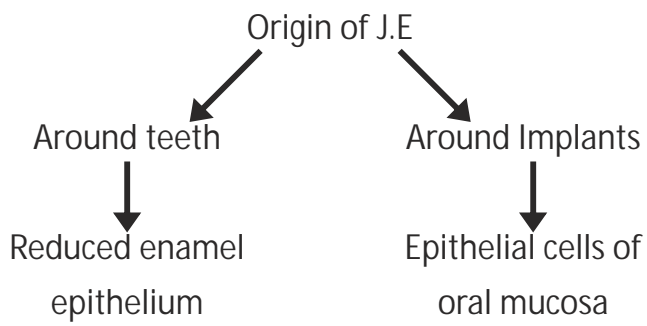

Hence, it is the subject of interest whether or not these $2 \mathrm{~J}$.E is identical in their structural and functional characteristics. However, although the 2 epithelia resemble similar structurally ${ }^{[4,46,47]}$, few dissimilarities have been reported ${ }^{[48,49,50]}$ (Figure 6)

Table 3:

\begin{tabular}{|c|c|c|}
\hline & HEALTHY TEETH & HEALTHY IM PLANTS \\
\hline Sulcuar depth & Shallow in absence of disease & $\begin{array}{l}\text { Sulcular depth varies, depending upon the length of abutment and } \\
\text { restorative margin. }\end{array}$ \\
\hline J.E & On the enamel surface & On the metal surface of the implant \\
\hline Biologic width & Supracrestal & Subcrestal \\
\hline \multirow[t]{2}{*}{ Gingival fibres } & Fibres inserted on to the & Collagen fibres are arranged in parallel fashion \\
\hline & $\begin{array}{l}\text { cementum above the crest } \\
\text { of the bone and arranged } \\
\text { in a complex manner }\end{array}$ & \\
\hline Crest of the bone & 1-2 mm apical to CEJ & $\begin{array}{l}\text { Crest of the bone varies } \\
\text { - According to the design of the implant } \\
\text { - If the implant surface is threaded then the crest of the bone lies about } \\
\text { the first thread }\end{array}$ \\
\hline Physical characteristics & $\begin{array}{l}\text { Slight mobility is present and } \\
\text { normal because of the } \\
\text { visoelastic properties of } \\
\text { periodontal ligament }\end{array}$ & No mobility present and resembles ankylosed unless infected \\
\hline Adaptive characteristics & $\begin{array}{l}\text { Adaptive capacity varies } \\
\text { according to the amount of } \\
\text { occlusal forces }\end{array}$ & $\begin{array}{l}\text { No adaptive capacity present due to the abscence of periodontal } \\
\text { ligament. }\end{array}$ \\
\hline Proprioception & $\begin{array}{l}\text { Good proprioception because } \\
\text { of presence of high sensitive } \\
\text { receptors }\end{array}$ & No proprioception. \\
\hline
\end{tabular}

FEW KEY SLMILARITIES BETWEEN IMPLANT EPITHELIUM JUNCTION \& JUNCTIONAL EPITHELIUM:

Epithelial cells in both the epithelia are attached to the tooth by hemidesmosomes.

$>$ A viable biologic seal exists between both the epithelia

$>$ Sulcus around the implant is also lined by sulcular epithelium which is continuous with $\mathrm{J} \mathrm{E}$

$>$ Capillary loops under both the epithelia appear to be similar

$>$ Certain marker molecules of defense mechanism against bacterial challenge like t- PA. ICAM-1, cytokeratin profile etc., appear similar to that of gingival J.E

\section{Histochemical Aspects of normal Junctional Epithelium ${ }^{[51,52]}$}

Histochemical techniques are considered important as they provide knowledge regarding various enzyme systems and chemical components that appear in normal gingiva which help us in appreciating physiologic processes in the gingiva and the changes that occur in disease. Following are various cellular and intercellular substances and enzymes that can be appreciated in the normal gingiva.

\section{Cellular and intercellular substances}

1. Heteropolysaccharide which stains PAS tve is an intercellular ground substance seen between the cells of 
the epithelium.

2. Acid mucopolysaccharides, hyaluronic acid, chondroitin sulfate $A, C$ and $B$ etc., PAS - ve are present between the epithelial cells, and are considered by some investigators to be intercellular cementing substance and by others to be certain stained portions of intercellular attachment apparatus.

3. PAS tve glycogen is present in the epithelium in concentrations inversely related to the amount of keratinisation.

4. Normally sulfhydryls and disulfides bonds are present in the gingival epithelium.

5. The DNA and RNA activity of the epithelium at the gingival margin and junctional epithelium is greater than in the remaining oral mucosa.

Enzymes

Various enzymes found to be present in the J.Eare:

"Collagenase

"Alkaline phosphatase

"Lysosomes

"Diphospho and triphosphopyridine nucleotide reductase

"Cytochromic oxidase

\section{Regeneration of the junctional epithelium:}

Because of its anatomical location, injury of J.E may occur through various mechanical methods or clinical probing or through some intentional trauma.

"Clinical Probing:

Clinical probing disrupts J.E cells mechanically from the tooth surface. Several studies focused on whether and how fast a new epithelial attachment can be reformed. An experimental study done in marmosets was shown that 5 days after complete separation of J.E following clinical probing, a new epithelial attachment was established.

In another study it was shown that epithelial seal around implants was re-established within about the same time period following clinical probing. ${ }^{[53]}$ Based on the findings of these 2 studies, clinical probing around implants and natural teeth does not lead to irreversible damage of the soft tissue components.

$\varnothing$ Oral Hygiene Practices:

Regular oral hygiene practices may cause unintentional trauma to J.E. Waerhaug (1981) reported that following the use of dental floss in 12-year-old humans at premolar regions and after cessation of flossing there is detachment of cells which persisted for 24 hours and then new epithelial reattachment started within 3 days. ${ }^{[54]}$

" Gingivectomy:

Oral hygiene never completely removes J.E from tooth surface. However, the application of gingivectomy techniques would completely remove J.E. Subsequently, the formation of a new J.E must occur from basal cells of the oral gingival epithelium.

In humans, a new J.E after gingivectomy may form within 20 days indicating that it is a highly dynamic tissue with a fast self-renewal capacity. ${ }^{[5]}$

"Scaling And Root Planing

JEforms in 2 weeks after phase I therapy. ${ }^{[56]}$

"Open Flap Debridement

Formation of long J. E occurs in 4-6 months. ${ }^{[57]}$

"M ucogingival Surgery:

It takes 3-4 weeks and the stages involved are: - adaptation, proliferation, attachment and maturation. ${ }^{[58]}$

\section{Conclusion}

Junctional epithelium is a unique tissue that fulfils a challenging function at the border between the oral cavity, colonized by bacteria, and the tooth attachment apparatus. It is structurally and functionally very welladapted to control the constant bacterial ingress. Its structural alteration is clearly the first step towards the progression of disease. The conversion of the J.E to pocket epithelium is regarded as a hallmark in the development of periodontitis. Thus, understanding the molecular architecture and function of the junctional epithelium attachment may aid in the understanding the onset and progression of periodontal disease and may provide new possibilities for manipulating periodontal healing. 


\section{References}

1. Gao Z, Mackenzie C: Patterns of phenotypic expression of human junctional, gingival and reduced enamel epithelia in vivo and in vitroDental Branch/Dental Science Institute, University of Texas, Houston 77335.Epithelial Cell Biology [1992, 1(4):156-167]

2. Bosshardt D.D. and Lang N.P. The Junctional Epithelium: from Health to Disease J Dent Res 84(1):9-20, 2005

3. AAP- Periodontal literature review 1996; Definition of junctional epithelium

4. Thilander $\mathrm{H}$, Hugoson $\mathrm{A}$. The border zone tooth-enamel and epithelium after periodontal treatment. An experimental electron microscopic study in the cat. ActaOdontol Scand. 1970 Mar; 28(1):147-55.

5. Hubert E. Schroeder and M axA. Listgarten: The Junctional Epithelium: From Strength to Defense; Dent Res 2003;82(3):158-161.

6. Irving B. Stern; Current Concepts of the Dentogingival Junction: The Epithelial and Connective Tissue Attachments to the Tooth; J.Periodontol.September, 1981, 52(9).

7. Periodontal literature reviews 1996, Chapter 2. Periodontal diseases, Volume.1996, First edition: 12-35

8. Salonen JI, Kautsky MB, Dale BA (1989.Changes in cell phenotype during regeneration of junctional epithelium of human gingiva in vitro. J Periodontal Res 24:370-377.

9. Textbook of dental and oral histology with embryology; Satish Chandra, shaleen Chandra, 2004, Page 200

10. Gargiulo AW, WentzF, Orban B (1961). Dimensions and relations of the dentogingival junction in humans. J Periodontol 32:261-267.

11. Hassanpour.S, Tamam.S ,Shigapov.T:Clinical diagnosis \& guidelines; International Dental Journal of Student's Research,2015;3(2):52

12. Salonen JI, Kautsky MB, Dale BA (1989). Changes in cell phenotype during regeneration of junctional epithelium of human gingiva in vitro. J Periodontal Res 24:370-377.

13. Ishikawa H, Hashimoto S, Tanno M, Ishikawa T, Tanaka T, Shimono M. Cytoskeleton and surface structures of cells directly attached to the tooth in the rat junctional epithelium. J Periodont Res 2005; 40: 354-363.

14. OvermanD.o and Salonen J.I: Characterization of the Human Junctional Epithelial Cells Directly Attached to the Tooth (DAT Cells)in Periodontal Disease; J Dent Res, 1994;73(12):1818-1823

15. Lange D, Schroeder HE (1971). Cytochemistry and ultrastructure of gingival sulcus cells. HelvOdontolActa 15(Suppl 15):65-86.

16. Steinert PM , Jones JCR, Goldman RD .Intermediate filaments.J cell boil 1984; $99: 22 \mathrm{~s}-27 \mathrm{~s}$.

17. J uhl M ,Reibel J,StoltzeK; Immunohistochemical distribution of keratin proteins in clinically healthy human gingival epithelia. Scand J Dent Res 1989; 97:159-170.

18. Feghali-Assaly M 1, Sawaf MH, Serres G, Forest N, Ouhayoun JP. Cytokeratin profile of the junctional epithelium in partially erupted teeth. J Periodontal Res. $1994 \mathrm{M}$ ay;29(3):185-95

19. Attström R. Presence of leukocytes in crevices of healthy and chronically inflamed gingivae. J Periodontal Res 1970; 5:42-47.

20. Rashmi SM , Alka DK, Ramakant SN. Neutrophils in health and disease: An overview. Journal of oral and maxillofacial pathology 2006:10:1:38.

21. Hormia M, Owaribe K, Virtanen I. The dento-epithelial junction: cell adhesion by type I hemidesmosomes in the absence of a true basal lamina.J Periodontol 2001; 72:788-797.

22. Oyarzun-Droguett A . Ultracytochemical localization of basal lamina anionic sites in the rat epithelial attachment apparatus. J PeriodontalRes 1992; 27:256-263.

23. Sawada T, Yamamoto T, Yanagisawa T, Takuma S, Hasegawa $H_{\text {, }}$ Watanabe K. Electron-immunocytochemistry of laminin and type-IV collagen in the junctional epithelium of rat molar gingiva. J PeriodontalRes 1990; 25:372-376

24. Andrew LHarris and Darren Locke. Connexins, A Guide. New York: Springer. p. 574. ISBN 2009; 978-1-934115-46-6.
25. Yan $\mathrm{HH}, \mathrm{M}$ ruk DD, Lee WM, Cheng CY. "Cross-talk between tight and anchoring junctions-lesson from the testis". Adv. Exp. Med. Biol. 2008; 636: $234-5$

26. White, Thomas W.; Paul, David L. "Genetic diseases and gene knockouts reveal diverse connexin functions". Annual Review of Physiology1999; 61 (1): 283-310

27. Chalcroft, J. P.; Bullivant, S. "An interpretation of liver cell membrane and junction structure based on observation of freeze-fracture replicas of both sides of the fracture". The Journal of Cell Biology 1970; 47 (1): 49-60.

28. Nagata E, Kondo T, Ayasaka N, Nakata M, and Tanaka T. Immunohistochemical study of nerve fibres with substance $\mathrm{P}$ - or calcitonin gene-related peptide-like immunoreactivity in the junctional epithelium of developing rats. Arch. Oral Biol.1992; 37: 655-662.

29. Kondo T, Kido M A, Kiyoshima T, Yamaza T, and Tanaka. An immunohistochemical and monastral blue-vascular labelling studyon the involvement of capsaicin-sensitive sensory innervation of the junctional epithelium in neurogenic plasma extravasation in the rat gingiva. Arch. Oral Biol 1995; 40: 931-940.

30. Tanaka T, Kido M A, Ibuki T, Yamaza T, Kondo T, and Nagata E . Immunocytochemical study of nerve fibers containing substance $P$ inthe junctional epithelium of rats. J. Periodont. Res.1996; 31: 187- 194.

31. Skougaard M. Turnover of the gingival epithelium in marmosets.Acta Odontol Scand 1965; 23:623-643.

32. Schroeder $H E$, Listgarten M. Fine structure of developing epithelial attachment of human teeth. In: Monographs in developmental biology,Vol. 2. WolskyA, editor. Basel: 1971; Karger, pp.1-134.

33. Schiött CR, Löe H. The origin and variation in number of leukocytes in the human saliva. J Periodontal Res 1970; 5:36-41.

34. Lamster IB, Novak MJ.Host mediators in gingival crevicular fluid: implications for the pathogenesis of periodontal disease. Crit Rev Oral Biol Med. 1992;3(1-2):31-60.

35. Hillmann G, Vipismakul V, Donath K. Die Entstehung plaquebedingter Gingivataschen im Tiermodell. Eine histologische Studie an unentkalkten Dünnschliffen. Dtsch Zahnärztl .19900;45:264-266

36. Takata $T$, Donath $K$.The mechanism of pocket formation. A light microscopic study on undecalcified human material. J Periodontol 1988; 59:215-221.

37. Kowashi Y, Jaccard F, Cimasoni G. Sulcular polymorphonuclear leucocytes and gingival exudate during experimental gingivitis in man J Periodontal Res.1980; 15:151-158.

38. Schroeder HE, Attström R. Pocket formation: a hypothesis. In: The borderland between caries and periodontal disease II. Lehner T, Cimasoni G, editors. London, New York: Academic Press/Grune $\&$ Stratton, 1980; pp. 99-123.

39. Schroeder HE, Listgarten MA (1997). The gingival tissues: The architecture for periodontal protection. Periodontol 2000 13:91-120

40. Lamont RJ, Oda D, Persson RE, Persson GR. Interaction of Porphyromonas gingivalis with gingival epithelial cells maintained in culture. Oral M icrobiol Immuno.1992; 7:364-

41. Lamont RJ, Chan A, Belton CM, Izutsu KT, Vasel D, Weinberg A Porphyromonas gingivalis invasion of gingival epithelial cells. Infect Immun. 1995; 63:3878-3885.

42. Sandros J, Papapanou PN, Nannmark U, Dahlén G.Porphyromonas gingivalis invades human pocket epithelium in vitro. J Periodontal Res, 1994; 29:62-69

43. Potempa J, Banbula A, Travis J. Role of bacterial proteinases in matrix destruction and modulation of host responses. Periodontol 2000 24:153-192.

44. Curtis MA, Aduse-Opoku J, Rangaraja. Cysteine proteases of Porphyromonas gingivalis. Crit Rev Oral Biol M ed, 2001; 12:192-216.

45. Cochran DL. The scientific basis for and clinical experiences with Straumann implants including the ITI Dental Implant System: a consensus report. Clin Oral Implants Res 2000; 11(Suppl 1):33-58.149. 
46. Inoue T, Takeda T, Lee CY, Abiko Y, Ayukawa Y, Tanaka T, et al. Immunolocalization of proliferating cell nuclear antigen in the periimplant epithelium. Bull Tokyo Dent Coll 1997; 38:187-193.

47. Ikeda H, Yamaza T, Yoshinari M, Ohsaki Y, Ayukawa Y, Kido M A, et al. Ultrastructural and immunoelectron microscopic studies of the periimplant epithelium-implant (Ti-6Al-4V) interface of rat maxilla. J Periodontol 2000; 71:961-973.

48. Fujiseki M, Matsuzaka K, Yoshinari M, Shimono M, Inoue . An experimental study on the features of peri-implant epithelium: immunohistochemical and electron microscopic observations. Bull Tokyo Dent Coll 2003; 44:185-199

49. Yuichi Izumi, Shinichi Arakawa: Implants and clinical dentistry; Field of Periodontology, Graduate School of M edical and Dental Studies, Tokyo Medical and Dental University.

50. Schmid B, Spicher I, Schmid J, Lang NP. Plasminogen activator in human gingival tissue adjacent to dental implants. Clin Oral Implants 1992; $3(2): 85-9$.

51. Halacková Z, Oudrán L, Kukletová M .Localization of some enzymes in the periodontium of the rat molar. Acta Histochem. 1980; 67(2):173-9.

52. Carneiro and De Moraes, F. F., Radioautographic visualization of collagen metabolism in the periodontal tissue of the mouse. Arch. oral Biol. 1965; 10, 833- 848.

53. Etter TH, Hakanson I, Lang NP, Trejo PM , Caffesse RG (2002). Healing after standardized clinical probing of the periimplant soft tissue seal: a histomorphometric study in dogs. Clin Oral Implants Res 13:571-580.

54. Waerhaug J: Healing of the dento-epithelial junction following the use of dental floss; Journal of Clinical Periodontology: 1981: 8: 144-150

55. Innes PB (1970). An electron microscopic study of the regeneration of gingival epithelium following gingivectomy in the dog. J Periodontal Res 5:196-204.

56. Waerhaug J. Healing of the dento-epithelial junction following subgingival plaque control. II: As observed on extracted teeth. J Periodontol 1978; 49(3):119-34.

57. Froum SJ, Kushner L, Stahl SS. Healing responses of human intraosseous lesion following the use of debridement, grafting and citric acid root treatment.Clinical and histologic observations 6 months post-surgery.J periodontol 1983:54:67-76

58. Wilderman M N, Pennel BM , King K, Barron JM. Histogenesis of repair following osseous surgery. Journal of Periodontology. 1970; 41(10):551-565. 